\title{
Comparing Experiment and Computation of Hypersonic Laminar Boundary Layers with Isolated Roughness
}

\author{
Brett F. Bathel* \\ NASA Langley Research Center, Hampton, Virginia, 23693, USA \\ Prahladh S. Iyer, ${ }^{\dagger}$ Krishnan Mahesh ${ }^{\ddagger}$ \\ University of Minnesota, Minneapolis, Minnesota, 55455, USA \\ Paul M. Danehy, ${ }^{\S}$ Jennifer A. Inman, ${ }^{* *}$ Stephen B. Jones ${ }^{\dagger \dagger}$ \\ NASA Langley Research Center, Hampton, Virginia, 23693, USA \\ and \\ Craig T. Johansen \\ University of Calgary, Calgary, Alberta, T2N 1N4, Canada
}

\begin{abstract}
Streamwise velocity profile behavior in a hypersonic laminar boundary layer in the presence of an isolated roughness element is presented for an edge Mach number of 8.2. Two different roughness element types are considered: a 2-mm tall, 4-mm diameter cylinder, and a 2-mm radius hemisphere. Measurements of the streamwise velocity behavior using nitric oxide (NO) planar laser-induced fluorescence (PLIF) molecular tagging velocimetry (MTV) have been performed on a 20-degree wedge model. The top surface of this model acts as a flat-plate and is oriented at 5 degrees with respect to the freestream flow. Computations using direct numerical simulation (DNS) of these flows have been performed and are compared to the measured velocity profiles. Particular attention is given to the characteristics of velocity profiles immediately upstream and downstream of the roughness elements. In these regions, the streamwise flow can experience strong deceleration or acceleration. An analysis in which experimentally measured MTV profile displacements are compared with DNS particle displacements is performed to determine if the assumption of constant velocity over the duration of the MTV measurement is valid. This assumption is typically made when reporting MTV-measured velocity profiles, and may result in significant errors when comparing MTV measurements to computations in regions with strong deceleration or acceleration. The DNS computations with the cylindrical roughness element presented in this paper were performed with and without air injection from a rectangular slot upstream of the cylinder. This was done to determine the extent to which gas seeding in the MTV measurements perturbs the boundary layer flowfield.
\end{abstract}

\section{Nomenclature}

$d \quad=$ isolated roughness diameter, $\mathrm{mm}$

$d x, d z \quad=\quad$ streamwise and spanwise computational grid spacing, $\mathrm{mm}$

$\Delta x=$ streamwise displacement, $\mathrm{mm}$

\footnotetext{
* Research Scientist, Advanced Sensing and Optical Measurement Branch, MS 493, AIAA Member.

${ }^{\dagger}$ Graduate Student, Department of Aerospace Engineering and Mechanics, AIAA Student Member.

* Professor, Department of Aerospace Engineering and Mechanics, AIAA Associate Fellow.

${ }^{\S}$ Research Scientist, Advanced Sensing and Optical Measurement Brach, MS 493, AIAA Associate Fellow.

** Research Scientist, Advanced Sensing and Optical Measurement Brach, MS 493.

${ }^{\dagger}$ Research Technician, Advanced Sensing and Optical Measurement Brach, MS 493.

$\$$ Assistant Professor, Department of Mechanical \& Manufacturing Engineering, AIAA Member.
}

1

American Institute of Aeronautics and Astronautics 


\begin{tabular}{|c|c|c|}
\hline$C F D$ & $=$ & computational fluid dynamics \\
\hline$D$ & $=$ & differential operator, $\partial / \partial y$ \\
\hline DNS & $=$ & direct numerical simulation \\
\hline$H$ & $=$ & computational domain height \\
\hline$L_{D}$ & $=$ & downstream computational domain distance \\
\hline$L_{U 1}$ & $=$ & computational inflow distance \\
\hline$L_{U}$ & $=$ & upstream computational domain distance \\
\hline$L_{z}$ & $=$ & spanwise computational domain extent \\
\hline$M_{e}$ & $=$ & edge Mach number (Mach number at $y=\delta_{L}$ ) \\
\hline MTV & $=$ & molecular tagging velocimetry \\
\hline NO & $=$ & nitric oxide \\
\hline$k$ & $=$ & isolated roughness height, $\mathrm{mm}$ \\
\hline$P_{e}, P_{w}$ & $=$ & edge and wall pressures, $\mathrm{Pa}$ \\
\hline PLIF & $=$ & planar laser-induced fluorescence \\
\hline$R e_{k}$ & $=$ & isolated roughness Reynolds number \\
\hline$t$ & $=$ & time, $\mathrm{s}$ \\
\hline$\Delta t$ & $=$ & effective time delay, s \\
\hline$T_{e}, T_{w}$ & $=$ & edge and wall temperatures, $\mathrm{K}$ \\
\hline$U$ & $=$ & streamwise velocity, m/s \\
\hline$U_{e}$ & $=$ & edge streamwise velocity, $\mathrm{m} / \mathrm{s}$ \\
\hline$x$ & $=$ & streamwise position, mm \\
\hline$x_{i n j}$ & $=$ & streamwise mass injection location, mm \\
\hline$x_{r}$ & $=$ & streamwise location of isolated roughness element, mm \\
\hline$X_{\text {trans }}$ & $=$ & streamwise transition-to-turbulence location in the absence of an isolated roughness element, mm \\
\hline$X_{\text {trans, } k}$ & $=$ & streamwise transition-to-turbulence location with an isolated roughness element present, mm \\
\hline$y$ & $=$ & wall-normal position, mm \\
\hline$z$ & $=$ & spanwise position, mm \\
\hline$\delta_{L}$ & $=$ & laminar velocity boundary layer thickness, mm \\
\hline$\mu$ & & dynamic viscosity, $\mathrm{m}^{2} / \mathrm{s}$ \\
\hline$\rho$ & $=$ & density, $\mathrm{kg} / \mathrm{m}^{3}$ \\
\hline
\end{tabular}

\section{Introduction}

$\mathrm{T}$ HE presence of a three-dimensional isolated roughness element in a hypersonic laminar boundary layer can influence the stability and transition-to-turbulence behavior of boundary layer flow. Typically, as the height of the roughness, $k$, relative to the thickness of the laminar velocity boundary layer, $\delta_{L}$, increases, the transition location moves further upstream. There is a particular height-to-thickness ratio for which the streamwise location of transition-to-turbulence, $x_{\text {trans, }}$, begins to deviate from the distance, $x_{\text {trans }}$, at which transition would occur in the absence of such an element. ${ }^{1}$ The roughness size is deemed to be critical at the smallest $k / \delta_{L}$ for which $\left|x_{\text {trans }}-x_{\text {trans, }, k}\right|$ $>0$. As $k / \delta_{L}$ is further increased beyond its critical value, $x_{\text {trans, } k}$ rapidly moves upstream towards the streamwise location of the roughness element itself, $x_{r}$. Low-speed ${ }^{2}$ and high-speed ${ }^{3}$ examples of this critical and super-critical behavior can be found in the literature. As $k / \delta_{L}$ is increased, there is a point at which further increase to this ratio has no additional effect on $x_{\text {trans, }, \text {. A }}$ At this point, the roughness is deemed to be fully effective. Beyond this effective roughness size, increasing $k / \delta_{L}$ may only increase the magnitude of the disturbance imparted to the boundary layer. ${ }^{1}$ A common metric used to correlate transition location with roughness size is the roughness Reynolds number, $R e_{k}=\rho_{k} U_{k} k / \mu_{k}$, where density $(\rho)$, streamwise velocity $(U)$, and dynamic viscosity $(\mu)$ are evaluated at $k$. For most applications, $R e_{k}<25$ represents a bound for which a roughness element has no influence on transitionto-turbulence and is therefore sub-critical. ${ }^{1,2,4}$ However, this is a semi-empirical relation, and roughness Reynolds numbers less than 25 have been shown to induce instability. ${ }^{1}$ No universal physics-based theory exists that relates roughness Reynolds number and critical roughness for all roughness geometries and flow conditions. ${ }^{5}$ The same may be said of the relation between $R e_{k}$ and effective roughness.

In the absence of any roughness element, the laminar high-speed flow over a flat plate is susceptible to instability if its velocity profile contains a generalized inflection point, defined as a vertical location $y>y_{0}$ for which $D(\rho D U)=0$. Here, $D$ is the differential operator, $D \equiv \partial / \partial y$, and $y_{0}$ corresponds to the height in the boundary layer where the velocity relative to the edge velocity has the value $U / U_{e}=1-\left(M_{e}\right)^{-1}$. For an adiabatic 
wall, there is at least one point within the boundary layer satisfying this condition, ${ }^{6-8}$ and for a cold wall there can be two points that satisfy this condition. ${ }^{7,8}$

When an isolated roughness element is present, it can introduce instability into the boundary layer through several mechanisms. For isolated roughness elements of $R e_{k}<10$, streamwise vorticity may be generated. ${ }^{1}$ This can result in disturbance amplification via interaction with a stationary crossflow instability or Görtler vortices, ${ }^{1}$ which are associated with eigenmode growth for low disturbance environments. ${ }^{9,10}$ Included in this eigenmode instability growth family are the $1^{\text {st }}$ and $2^{\text {nd }}$ modes described by Mack. ${ }^{7,11}$ Growth of eigenmode disturbances is exponential, and transition estimates can be performed using methods such as the $e^{N}$ method. ${ }^{12} A s R e_{k}$ is increased, the magnitudes of the disturbances generated by the roughness element increase, and instability growth via the transient growth mechanism occurs. ${ }^{4}$ Growth of instabilities occurring via this mechanism is algebraic in nature ${ }^{9,13}$ and is greatest for stationary streamwise disturbances ${ }^{12}$ such as stationary streamwise vortices. ${ }^{4}$ This instability mechanism then provides a higher amplitude disturbance to the eigenmode growth mechanism. ${ }^{9,10} \mathrm{As} R e_{k}$ is further increased, the transient growth mechanism continues to play a role, but the eigenmode growth mechanism is bypassed. ${ }^{12}$ Up to this value of $R e_{k}$, in addition to generating streamwise vorticity, an isolated roughness element will generate a shear layer in its wake. This shear layer may be convectively unstable, such that the instabilities grow as they progress downstream, in which case it may be the dominant instability mechanism leading to transition. ${ }^{14}$ However, for higher Mach number flows, a shear layer becomes more stable, and the convective instability mechanism may be suppressed. ${ }^{1}$ For roughness elements with sufficiently large values of $R e_{k}$ and with $k \approx \delta_{L}$, a significant wake region and shear layer is generated along with streamwise vorticity originating from a separation region upstream of the element. Experiments and computations of a cylindrical roughness element in a $M_{e}=6$ boundary layer have shown that for $R e_{k}>6 \times 10^{4}$ and $k / \delta_{L}>1$, the wake region is subject to an absolute instability resulting from oscillation of horseshoe vortices in the separation region ahead of the roughness element and an unstable shear layer. ${ }^{14}$ Computations of a $k / \delta_{L}=2.54$ hemispherical roughness element in a $M_{e}=3.37$ boundary layer also showed unsteady behavior in the separation region ahead of the element and the breakdown of streamwise vortices accompanied by the formation of hairpin vortices in the wake of the element, followed by the onset of transition. ${ }^{15,16}$ The formation of hairpin vortices was also affected by the interaction between an unsteady shear layer (emanating from the top of the trip) and the streamwise vortices along the centerline in the wake of the roughness. ${ }^{17,18}$

For a large, isolated roughness element where $k / \delta_{L}$ approaches unity, the applicability of linear stability methods comes into question. ${ }^{15,19}$ While some computations and experiments have been performed to gain insight into the transition-to-turbulence mechanism for these elements, it remains unclear as to what conditions lead to an element being sub-critical, critical, or effective and what role convective and absolute instabilities play. ${ }^{1,20}$ However, it does appear that the separation region just upstream of the roughness element and the shear layer play important roles in large-roughness-induced transition-to-turbulence, and an improved understanding of these flowfield features is required.

Qualitative flow visualization and quantitative velocimetry experiments have been performed at NASA Langley Research Center with the goal of improving the understanding of the flow physics associated with both hemispherical and cylindrical isolated roughness elements in hypersonic laminar boundary layers. Flow visualization experiments with hemispherical ${ }^{21}$ and cylindrical ${ }^{22-24}$ isolated roughness elements using nitric oxide (NO) planar laser-induced fluorescence (PLIF) imaging have been used in qualitative comparisons with computational studies of hemispheres ${ }^{17}$ and cylinders. ${ }^{25}$ Quantitative streamwise velocity measurements ${ }^{26}$ using NO molecular tagging velocimetry (MTV) have been used to validate direct numerical simulation (DNS) results in a Mach 8 hypersonic boundary layer along the centerline of a flat surface with a cylindrical roughness element for $\mathrm{k} / \delta_{L}=0.64 .{ }^{15}$ In that comparison of NO MTV data with DNS results, relatively good agreement between experiment and computation was obtained at streamwise locations away from the roughness element. Both the experiment and computation showed that the boundary layer in the wake of the cylindrical roughness element remained laminar and the centerline shear layer emanating from the top of the roughness element gradually recovered to a Blasius-like profile with increasing streamwise distance. At streamwise locations ahead of the roughness element and immediately behind the roughness element, significant discrepancies between experimentally measured and computed streamwise velocities were observed.

One hypothesis for these discrepancies observed in Ref. 15 involves the influence an adverse pressure gradient ahead of the roughness element had on the MTV measurement. This pressure gradient is responsible for the separation region and a system of horseshoe vortices ahead of the roughness. The presence of an adverse pressure gradient would result in a local deceleration of the flow. Since the MTV technique is a time-of-flight technique, the velocity corresponding to the initial streamwise location of the tagged molecules is inferred by measuring their displacement imaged at two sequential times $\sim 500 \mathrm{~ns}$ apart. If instantaneous streamwise velocity of the tagged 
molecules is higher in the first image than in the second because of flow deceleration, the measurement will be biased towards lower velocities. In other words, the measurement does not strictly give the velocity at the initial location, but rather yields the weighted average of the changing velocity along the path traversed by the tagged molecule during the $500 \mathrm{~ns}$ measurement period. An analogous hypothesis can be made in regions with a favorable pressure gradient.

Another hypothesis for the discrepancies in Ref. 15 is that the injection of NO gas into the boundary layer at a location ahead of the isolated roughness element distorts the flowfield immediately downstream of the injection location. This injection of NO, which occurs at a location $x_{i n j}$ downstream of the leading edge, is necessary because NO serves as the tracer species for MTV measurements. Computations ${ }^{27}$ performed for a Mach 8 laminar boundary layer with an injection rate of $3 \mathrm{mg} / \mathrm{s}$ of $\mathrm{NO}$ showed that, at a location corresponding to $x / x_{i n j} \approx 3.6$, fairly small deviations in velocity and temperature were observed relative to a computation where no injection occurred. An analysis in Ref. 21, based on an injection study in Ref. 28, also suggested that such low blowing rates would have minimal influence on boundary layer transition-to-turbulence. However, it is unclear from these studies how the boundary layer flow just downstream of the injection location but ahead of the roughness element may be affected by such injection.

This paper has three objectives: (1) determine what influence NO mass injection may have on streamwise velocity (2) compare experimental streamwise velocity measurements with DNS computations to examine the influence of isolated hemispherical and cylindrical roughness elements on a $M_{e}=8$ hypersonic laminar boundary layer; and (3) use DNS to identify potential systematic measurement errors resulting from velocity gradients and/or orthogonal velocity components.

\section{Experimental Setup}

\section{A. Wind Tunnel Facility}

The experiments described in this paper were performed in the 31-inch Mach 10 Air blowdown wind tunnel facility at NASA Langley Research Center. The facility is described in Ref. 29 and a brief description is provided here. Air for the facility is supplied from a centralized bottle field to a pressurized chamber containing a $12.5 \mathrm{MW}$ electrical resistance heater. For the experiments described in this paper, the nominal stagnation pressure and stagnation temperature inside the chamber were $2.41 \mathrm{MPa}(350 \mathrm{psia})$ and $1000 \mathrm{~K}\left(1800{ }^{\circ} \mathrm{R}\right)$, respectively. The air passes through a settling chamber and filter prior to passing through a converging-diverging contoured nozzle with a 1.07-inch square throat. The flow is accelerated to a nominal Mach number of 10 as it expands through the nozzle into a 31-inch square test section. The stated pressure fluctuations within the inviscid core flow are $\pm 1.0 \%{ }^{29}$ Three large UV-transmitting windows are mounted flush to the top, side, and bottom interior walls of the test section. These windows are capable of transmitting light down to a wavelength of $190 \mathrm{~nm}$. The fourth sidewall contains a sliding door that separates the wind tunnel test section from the housing for the model injection system. Once the Mach 10 flow is established within the test section, this door is opened, and the wind tunnel model is injected into the flow via a hydraulic injection system. The sting used to support the wind tunnel model is mounted to an aerodynamic strut, which is capable of providing automated angle-of-attack control and manually adjusted yaw control.

\section{B. Wind Tunnel Model}

A 10-degree half-angle wedge model with a sharp leading edge was used in this experiment. The leading edge radius is less than $0.024 \pm 0.005 \mathrm{~mm}$. The upper surface of the wedge model, over which the NO MTV measurements and PLIF flow visualizations were made, was a stainless steel flat surface that was $127.0 \mathrm{~mm}$ (5 inches) wide and $162.5 \mathrm{~mm}$ (6.4 inches) long. The top surface was painted with a flat black high temperature paint to minimize laser scatter. The model pitch angle was oriented such that the upper flat surface was angled at 5-degrees with respect to the freestream. One of two different isolated roughness elements was positioned along the streamwise symmetry plane and centered at $75.4 \mathrm{~mm}$ downstream of the leading edge. The isolated roughness elements consisted of a 2$\mathrm{mm}$ tall, 4-mm diameter stainless steel cylinder and a 2-mm radius stainless steel hemisphere. Pure NO was seeded into the laminar boundary layer from an 11-mm-long, 0.81-mm-wide slot centered on the streamwise symmetry plane and 29.4-mm downstream of the leading edge. The nominal mass flowrate supplied through this slot was 3 $\mathrm{mg} / \mathrm{s}$ (150 standard cubic centimeters per minute, SCCM). The surface pressure was monitored by a Druck pressure gauge, model PDCR 4060, 0.04\% accuracy up to 5 psia. A thermocouple was attached to the underside of the model's 1/5-inch-thick stainless steel surface with Kapton ${ }^{\circledR}$ tape to measure the plate temperature. The placement of 
Table 1: Experimental conditions.

\begin{tabular}{|c|c|c|c|c|c|c|c|c|}
\hline Test-Run & View & Roughness & $T_{e}(K)$ & $\mathbf{P}_{\mathrm{e}}(\mathbf{P a})$ & $T_{w}(K)$ & $\mathbf{P}_{\mathrm{w}}(\mathbf{P a})$ & Laser Sheet (mm) & NO Flow Rate \\
\hline $462-18$ & Side & $\begin{array}{l}\text { Cylinder } \\
k=2 \mathrm{~mm} \\
d=4 \mathrm{~mm}\end{array}$ & 73.4 & 200.5 & 301.8 & 262.4 & $z=0.0 \mathrm{~mm}$ & 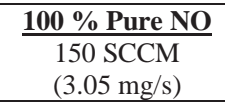 \\
\hline $462-25$ & Top & $\begin{array}{l}\text { Cylinder } \\
k=2 \mathrm{~mm} \\
d=4 \mathrm{~mm}\end{array}$ & 73.7 & 200.7 & $\begin{array}{l}295.7 \\
304.1 \\
300.5\end{array}$ & 255.3 & $\begin{array}{l}y=0.0 \mathrm{~mm} \\
y=2.2 \mathrm{~mm} \\
y=3.4 \mathrm{~mm}\end{array}$ & $\frac{100 \% \text { Pure NO }}{150 \mathrm{SCCM}}$ \\
\hline $477-5$ & Side & $\begin{array}{c}\text { Hemisphere } \\
k=2 \mathrm{~mm} \\
d=4 \mathrm{~mm}\end{array}$ & 73.6 & 200.9 & $\begin{array}{l}305.7 \\
309.7 \\
314.1 \\
318.5 \\
324.4\end{array}$ & 269.2 & $\begin{aligned} Z & =-1.42 \mathrm{~mm} \\
Z & =-0.41 \mathrm{~mm} \\
Z & =0.57 \mathrm{~mm} \\
Z & =1.58 \mathrm{~mm} \\
Z & =2.58 \mathrm{~mm}\end{aligned}$ & $\begin{array}{c}\mathbf{1 0 0} \% \text { Pure NO } \\
154.0 \text { SCCM } \\
\pm 0.4 \text { SCCM } \\
(3.13 \mathrm{mg} / \mathrm{s})\end{array}$ \\
\hline
\end{tabular}

the thermocouple provided only an estimate of the true plate temperature. The temperature measurement did not account for heat transfer effects occurring through the thickness of the plate.

\section{Laser and Imaging System}

The 532-nm output from a pulsed Spectra Physics Pro-230 Nd:YAG laser was used to pump a Sirah Cobra Stretch dye laser to achieve a 622-nm output beam. This output was mixed with 355-nm light from the Nd:YAG in a Sirah Frequency Conversion Unit to produce $226 \mathrm{~nm}$ output. This beam was directed to sheet-forming optics mounted above the tunnel test section. The duration of the pulse at this wavelength was approximately $9.5 \mathrm{~ns}$.

To form a laser sheet, the collimated $226 \mathrm{~nm}$ beam was passed through a cylindrical lens, which focused and then diverged the beam, expanding it in one direction while leaving it collimated in the other. A 1-m focal length spherical lens then collimated the diverging axis of the beam and focused the other axis into a thin sheet approximately $75-\mathrm{mm}$ wide by $0.5-\mathrm{mm}$ thick. To tag multiple lines of NO in the test section for a velocimetry measurement, a 50-mm-long, LaserOptik GmbH diffusion-welded lens array of 25 1-m focal length cylindrical lenses focused the laser sheet into 25 lines. The lens array had an anti-reflection coating.

Two different laser orientation and camera views were used to obtain the MTV images. In both cases, the camera was perpendicular to the plane containing the laser lines. The camera was first oriented such that axial velocity measurements were performed along a series of lines perpendicular to the plate and aligned with the centerline. This view is hereafter referred to as the side-view orientation. The second orientation was with the laser lines running parallel to the model surface in the spanwise direction. This view is hereafter referred to as the top-view orientation.

To image the tagged lines in both tests, a Cooke DiCAM-PRO camera, utilizing an intensified 1280x1024 pixel array interline progressive scan CCD, was used. The camera was fitted with a 100-mm focal length, F/2 Bernhard Halle Nachfolger GmbH lens. When used in double shutter mode, the camera is capable of acquiring an image pair with a minimum 500 ns delay between the end of the first gate and the beginning of the second. Each gate has a minimum duration of $20 \mathrm{~ns}$, with delay settings and durations set in increments of $20 \mathrm{~ns}$. A detailed discussion of the timing sequence methodology used in the NO PLIF experiments is provided in Refs. 26 and 30.

\section{Experimental and Image Processing Details}

Table 1 lists the experimental conditions used for the MTV hypersonic boundary layer measurements. Over the course of each run, small physical downward displacements of the model were observed. Presumably, the displacement is a result of non-uniform mechanical and thermal loading on the sting, which causes it to bend downward. Additionally for side view runs, the plate surface was at a slight angle $\left(<0.25^{\circ}\right)$ relative to the horizontal alignment of the camera's CCD array. For side-view runs, the raw images were translated upward and rotated using the function imwarp in MATLAB ${ }^{\circledR}$ with a cubic interpolation method to correct for model displacement and rotation. For the top-view run, this post-processing was not performed. As a result, the laser sheet position reported in Table 1 for the top-view run is estimated to be within $\pm 0.13 \mathrm{~mm}$ of the reported $y$-position.

Prior to plotting the experimental MTV velocity and displacement profile data presented in this paper, an effort was made to remove data points that appeared to be affected by laser scatter or reflections from the model surface. Data points near the boundary layer edge that had low signal-to-noise levels were also removed. This process of data

Table 2: Details of computational domain.

\begin{tabular}{lcccc}
\hline \hline Simulation Condition & $\boldsymbol{L}_{U} / \boldsymbol{d}$ & $\boldsymbol{L}_{\boldsymbol{D}} / \boldsymbol{d}$ & $\boldsymbol{L}_{\boldsymbol{z}} / \boldsymbol{d}$ & $\boldsymbol{H} / \boldsymbol{d}$ \\
\hline Cylindrical roughness & 10.0 & 22.0 & 10.0 & 10.0 \\
Cylindrical roughness with upstream injection & 17.5 & 22.0 & 10.0 & 10.0 \\
Hemispherical roughness & 10.0 & 40.0 & 20.0 & 20.0 \\
\hline \hline
\end{tabular}

American Institute of Aeronautics and Astronautics 
point removal was done on a profile-by-profile basis by the first author.

\section{Computational Procedure}

\section{A. Numerical Details}

The simulations use an algorithm developed by Park and Mahesh ${ }^{31}$ for solving the compressible Navier-Stokes equations on unstructured grids. The governing equations are discretized using a cell-centered finite volume scheme. The simulations employ a modified least-square method for face reconstruction, which is more accurate than a

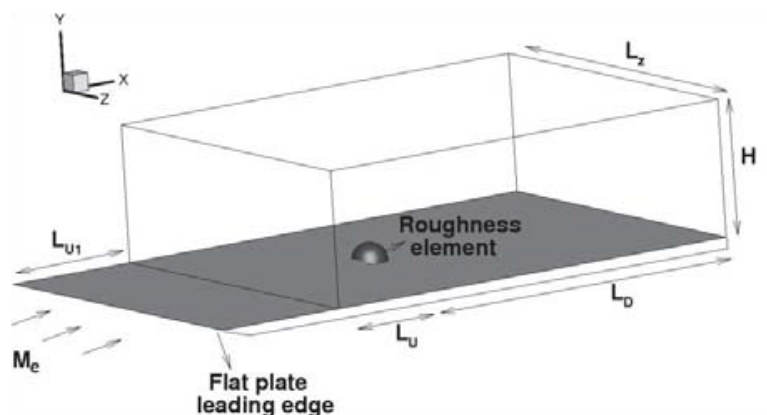

Fig. 1. Schematic of the computational domain. Taken from Ref. 16.

simple symmetric reconstruction, and more stable than a least-square reconstruction. The algorithm uses a novel characteristic-based filter shock-capturing scheme that localizes numerical dissipation to the vicinity of flow discontinuities. The solution is advanced in time using a second-order explicit Adams-Bashforth scheme. Additional information on the DNS methods used for the computations in this paper can be found in Refs. 15-18.

The numerical method has been used to study transition-to-turbulence induced by distributed roughness in a Mach 2.9 boundary layer ${ }^{32}$ and transition to turbulence using blowing and suction at Mach 2.25 where the turbulent statistics showed good agreement with experimental data under similar conditions. ${ }^{33}$ The algorithm has also been used to study the interaction of a supersonic jet with a subsonic cross-flow and a sonic jet with a supersonic crossflow, ${ }^{34}$ where a comparison of mean velocity profiles showed good agreement with experiments. Also, DNS of shock-turbulence interaction at Mach 2.9 in a compression corner ${ }^{35}$ was studied using the current methodology.

\section{B. Computational Details}

A schematic of the computational domain is shown in Fig. 1, taken from Ref. 16. $L_{U 1}$ is the distance of the inflow of the computational domain from the leading edge of the flat plate. $L_{U}, L_{D}$, $L_{z}$, and $H$ are the upstream, downstream, spanwise and vertical extents of the domain and are listed in Table 2 for the different simulations performed. The wall is maintained at a constant temperature of $300 \mathrm{~K}$. A compressible self-similar boundary layer solution is prescribed at the inflow. Non-reflecting sponge layer boundary conditions are used for the inflow, outflow, top, and side walls.

For the cylindrical roughness simulation with upstream injection, air is injected with a velocity of $73 \mathrm{~m} / \mathrm{s}$, pressure of $400 \mathrm{~Pa}$, and density of $0.0048 \mathrm{~kg} / \mathrm{m}^{3}$. This corresponds to a mass flow rate of $3.12 \mathrm{mg} / \mathrm{s}$. This injection occurred through a rectangular slot whose dimensions and location match those of the experiment (Section II.B). Although NO is injected in the experiment, we use air in the simulation to assess the effect of mass injection on the velocity profiles. The effects of NOair chemistry were not considered in this simulation, however previous

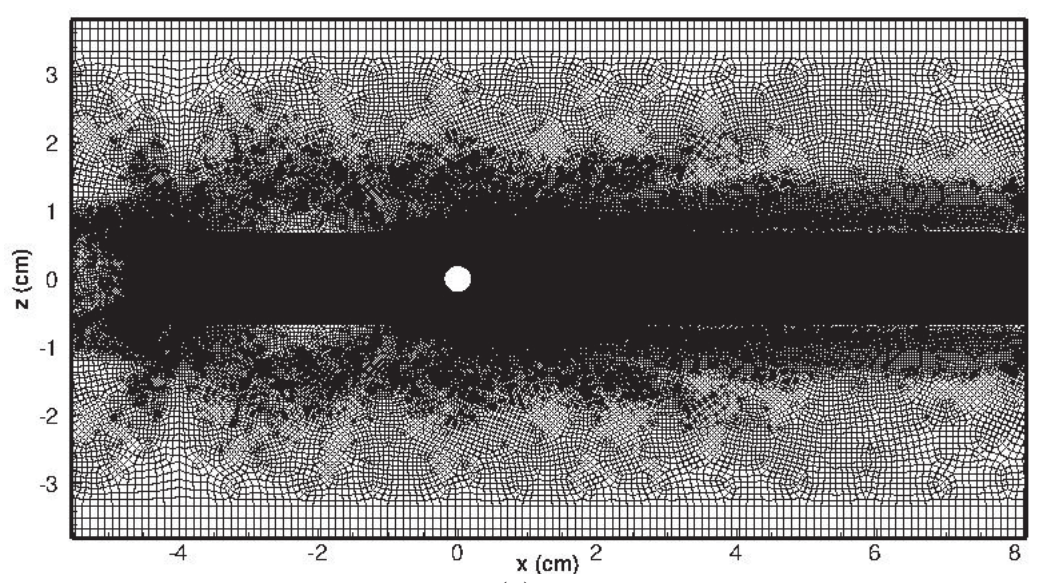

(a)

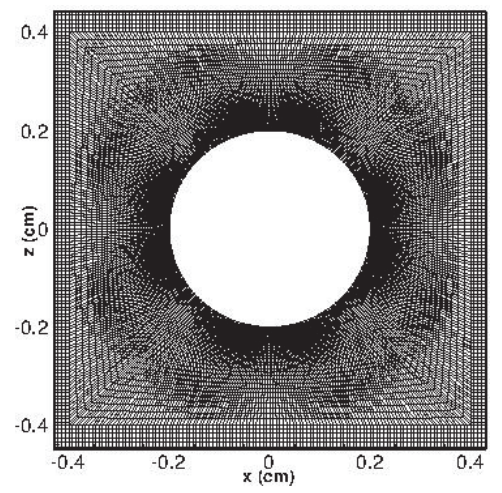

(b)

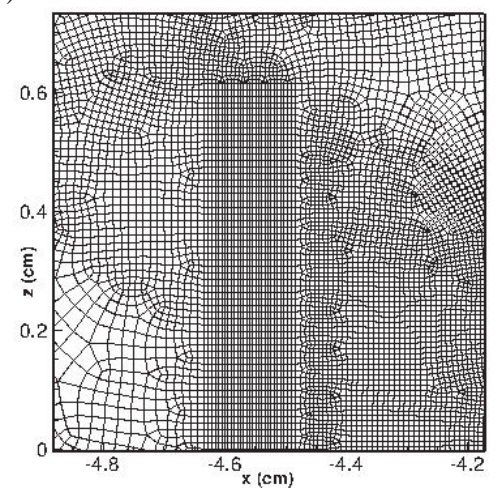

(c)

Figure 2. (a) Top-view of the grid for the cylindrical roughness with injection case. (b) Note the grid in the vicinity of the roughness and (c) in the vicinity of the slot for injection. 
computational work ${ }^{36}$ has suggested that such effects are negligible for the time scales of this flowfield.

A top view of the grid used for the cylindrical roughness case with injection is shown in Fig. 2. Note that the grid is fine in the vicinity of the roughness and coarsens in the laminar regions of the flow. There are 480 grid points in the circumference of the roughness and $30 \times 100$ points in the rectangular slot injection region. Downstream of the roughness, the grid spacing is approximately $d x \sim 0.066 \mathrm{~mm}$ and $d z \sim 0.07 \mathrm{~mm}$. There are approximately 25 points in the wall-normal $y$-direction within the height of the roughness with a minimum wall spacing of $0.04 \mathrm{~mm}$. The grid contains roughly 16 million grid points for all three cases simulated.

\section{Results}

\section{A. Effect of Upstream Injection on Boundary Layer Flowfield with Cylindrical Roughness}

To assess the effect of upstream injection in the experiment, we compare the velocity profiles obtained from the simulations with and without injection. The air injection is imposed as a boundary condition in the simulation to match the flow rate $(\sim 3 \mathrm{mg} / \mathrm{s})$ and physical properties of $\mathrm{NO}$ from the experiment. Figure 3a shows the instantaneous vertical velocity contours, normalized by $U_{e}$, in the symmetry plane for the cylindrical roughness case with upstream injection. Note the shock produced upstream of the roughness element and at the location of injection.

Figure $3 \mathrm{~b}$ shows instantaneous streamwise velocity contours, normalized by the edge velocity, $U_{e}$, in a wallparallel plane close to the wall. The wake behind the injection region is clearly visible and is indicated by a region of low velocity. Downstream of the roughness element, high-speed velocity streaks can be observed which are due to the streamwise vortices generated by the roughness element.

Figure 4a shows the side-view comparison of computed streamwise velocity profiles with (solid blue lines) and without (solid green lines) air injection in a plane located at $z=0.0 \mathrm{~mm}$, corresponding to Test-Run 462-18 in Table 1. The measured streamwise velocity profiles are also shown (black data points) from the MTV experiment. The width of the experimental data points corresponds to the uncertainty in the mean streamwise velocity. The vertical red lines correspond to the streamwise $x$-location where the velocity profiles were initially tagged in the experiment. The error in the profile $x$-locations is estimated to be $\pm 0.17 \mathrm{~mm}$. The light-gray rectangle in Fig. 4a corresponds to the spanwise projection of the isolated cylindrical roughness element.

In Fig. 4a, the simulated upstream air injection causes a significant increase in the boundary layer thickness, as can be observed at all streamwise locations. To confirm that the laminar boundary layer thickness at the inflow of the computational domain was prescribed correctly, we compare the velocity profiles at $z=40.0 \mathrm{~mm}$ for the injection case (far from the injection slot) with the symmetry plane profiles for the case without injection in Fig. 5. At $x=50.1 \mathrm{~mm}$ and $x=59.3 \mathrm{~mm}$, which is upstream of the roughness element, we see that the profiles with and without injection are nearly identical, indicating that the laminar boundary layer thickness at the inflow of the computational domain was prescribed correctly. It should be noted that the injection is prescribed as a steady boundary condition in the simulation. The injection slot mass flow rate has also been prescribed as a uniform $3.12 \mathrm{mg} / \mathrm{s}$, which neglects viscous effects that would otherwise result in a parabolic-like mass flow rate distribution. These two factors could potentially contribute to some differences in the boundary layer thickness observed with and without injection, although it is reasonable to expect that the boundary layer thickness would increase due to the injection.

In Fig. 4a, both the measurement and simulation show that a shear layer develops downstream of the cylindrical roughness element at $y=k=2.0 \mathrm{~mm}$. This shear layer recovers to a Blasius-like shape approximately 10 roughness diameters downstream of the roughness element. The magnitude of this shear layer is greater for the simulated case without air injection.

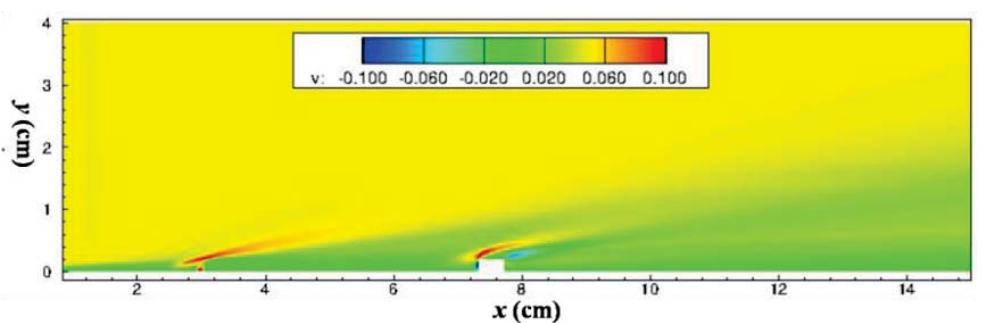

(a)

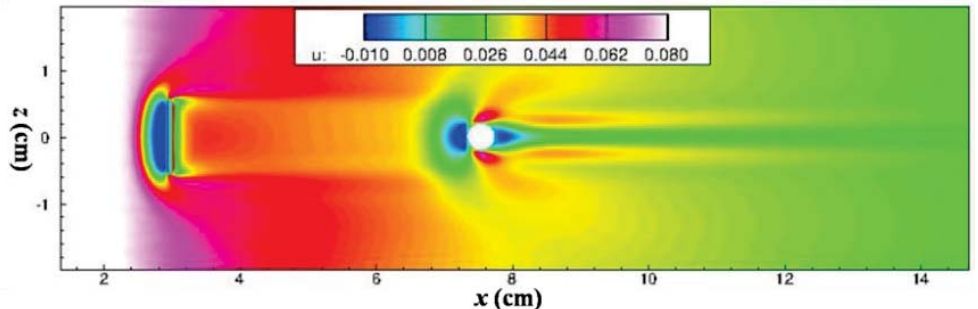

(b)

Fig. 3: (a) Symmetry plane $(z=0.0 \mathrm{~mm})$ wall-normal velocity contours normalized by $U_{e}$ for cylindrical roughness with upstream injection. (b) Wall-parallel plane streamwise velocity contours normalized by edge velocity for cylindrical roughness with upstream injection. 


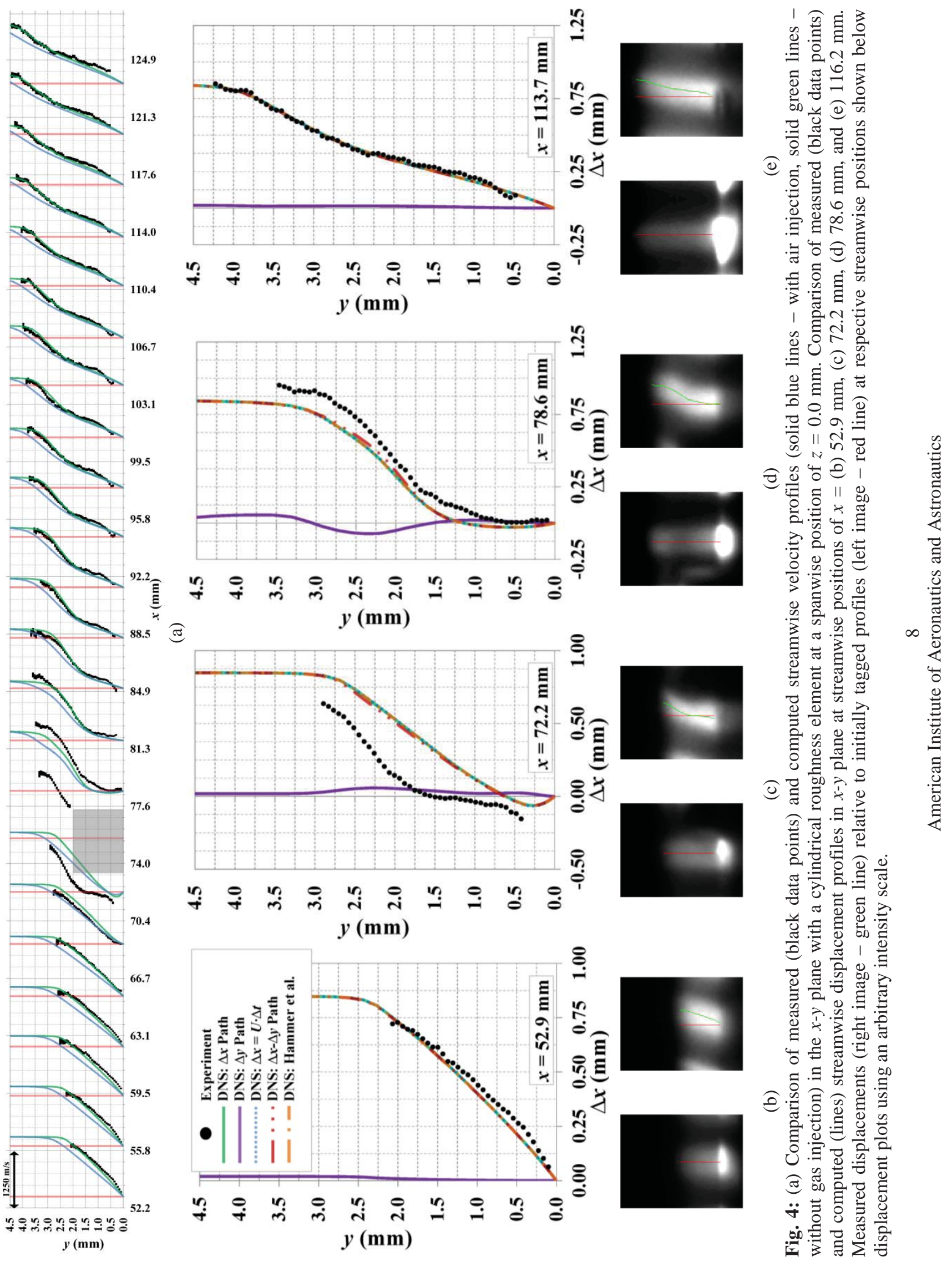




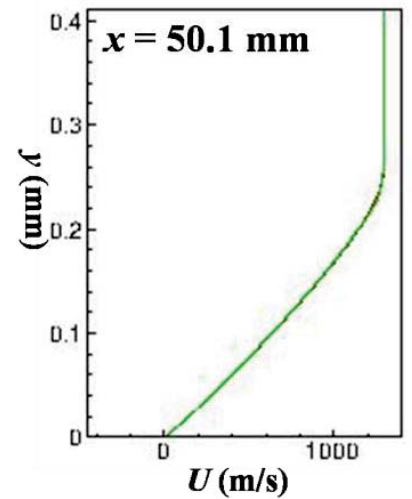

(a)

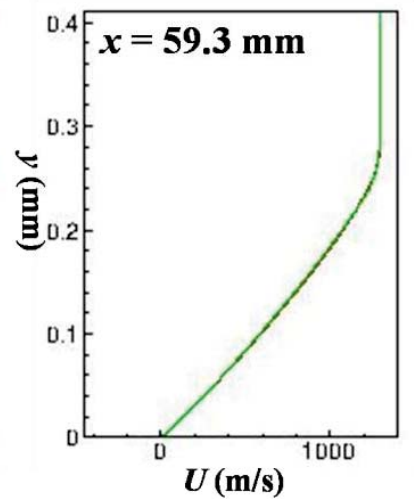

(b)

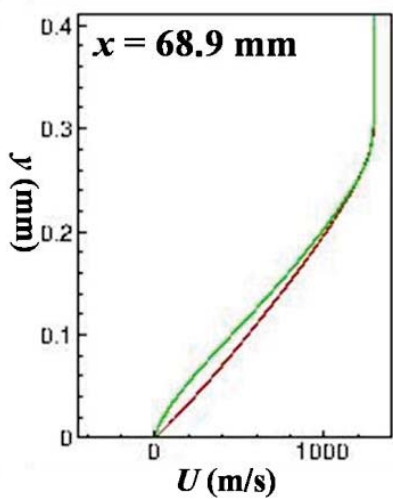

(c)

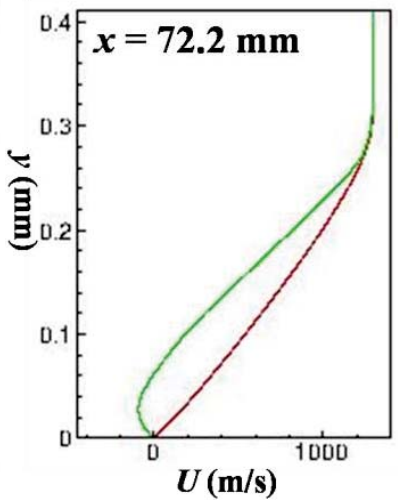

(d)

Fig. 5: Comparison of velocity profiles with upstream injection at $z=40.0 \mathrm{~mm}$ (solid red line) to velocity profiles without upstream injection (solid green line) along the $z=0.0 \mathrm{~mm}$ symmetry plane.

The simulation results presented in Fig. 4a indicate that the upstream injection of air could potentially cause a significant increase in the boundary layer thickness. When comparing the respective streamwise velocity profiles scaled by their respective local boundary layer thickness, computed as $\delta_{L}=y\left(U=0.99 \cdot U_{e}\right)$, we see that the scaled profiles are nearly identical, as shown in Fig. 6 . This suggests that the streamwise velocity distribution may scale with the upstream gas injection rate. However, comparison of the computed streamwise velocity profiles with the MTV measurements shows that the best general agreement between simulation and experiment occurs when considering the computed case without air injection. A similar result is observed when comparing simulation results without air injection with the MTV measurements in the top-view orientation in Figs. 7, 8a, and 9a.

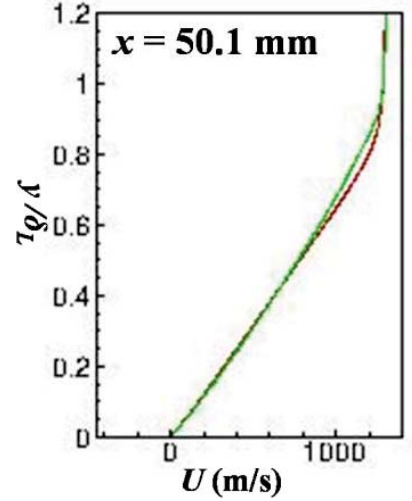

(a)

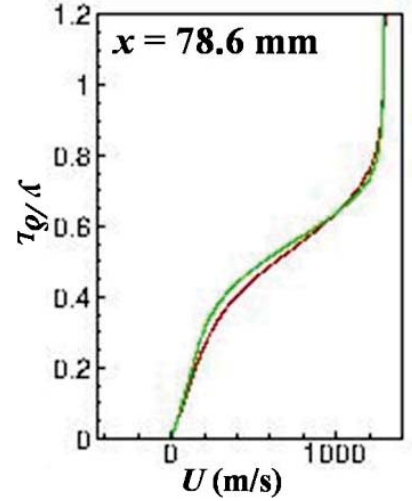

(e)

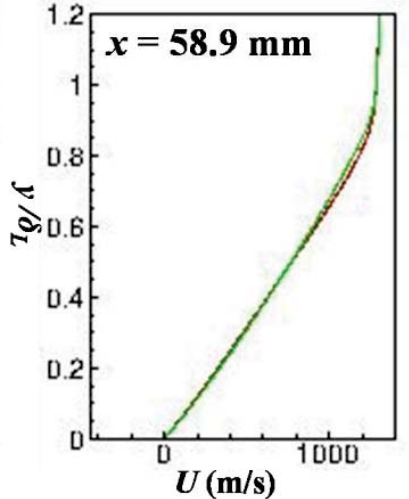

(b)

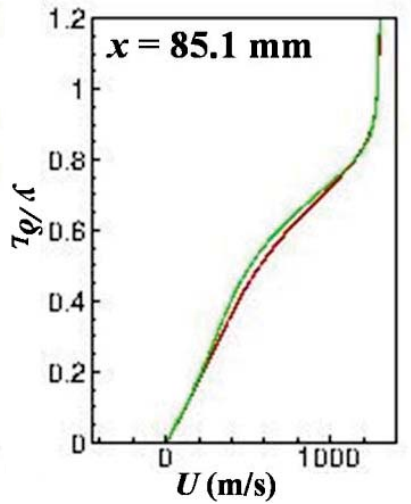

(f)

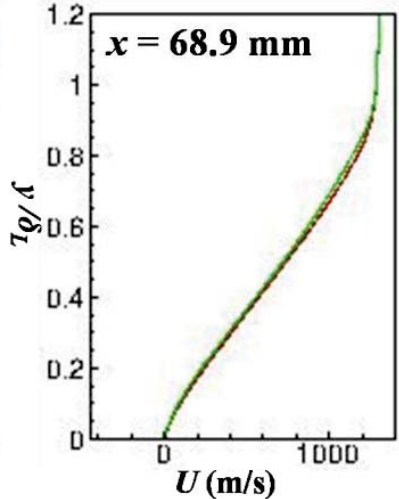

(c)

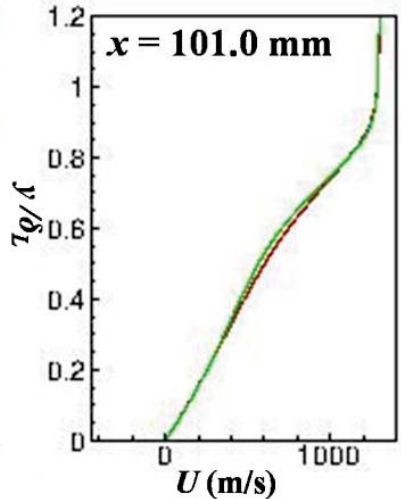

(g)

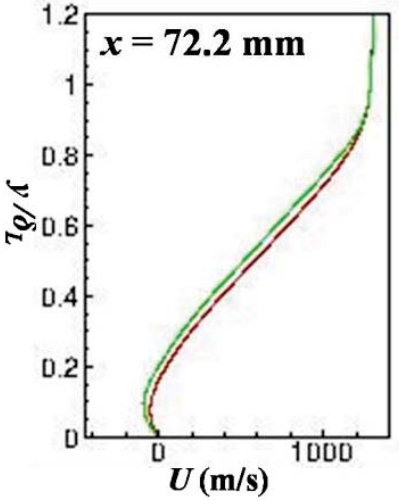

(d)

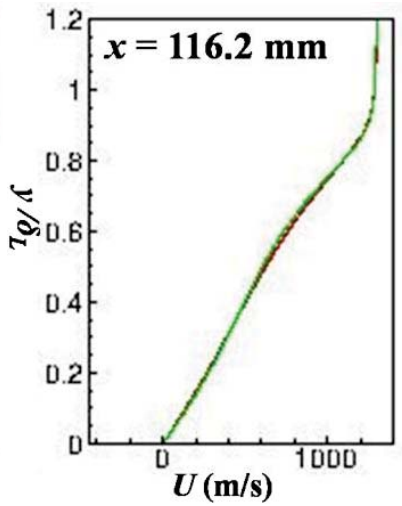

(h)

Fig. 6: Symmetry plane $(z=0.0 \mathrm{~mm})$ streamwise velocity profiles with (solid red lines) and without (solid green lines) upstream air injection. Profiles are scaled by the local boundary layer thickness, $\delta_{L}$, at the respective streamwise $x$-locations. 


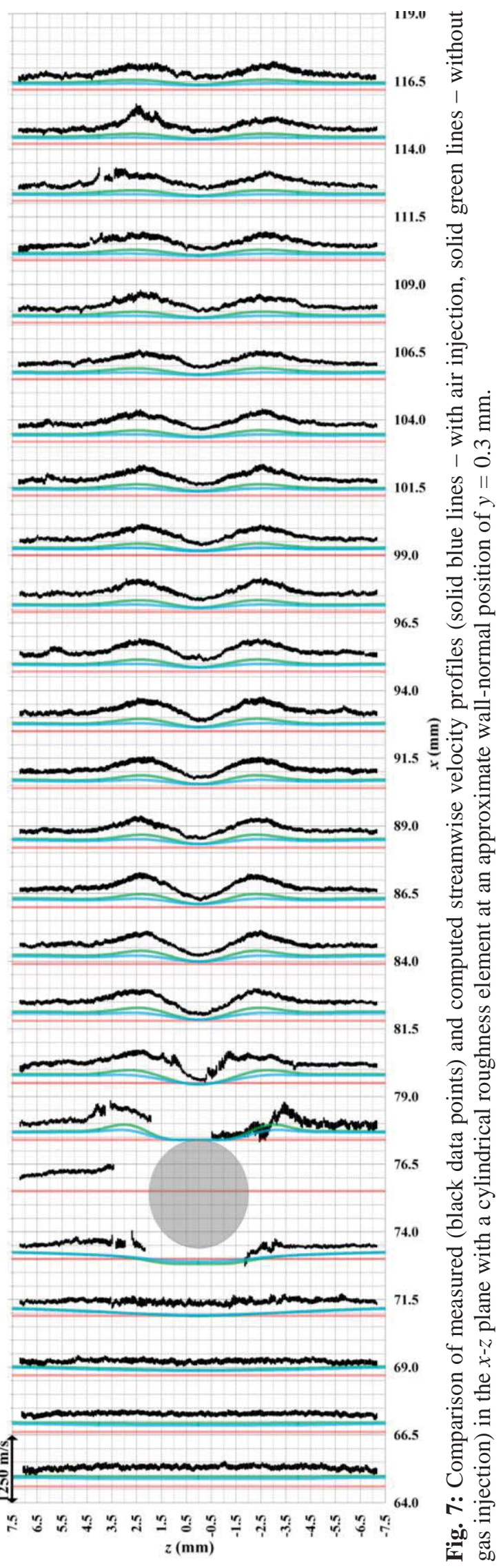



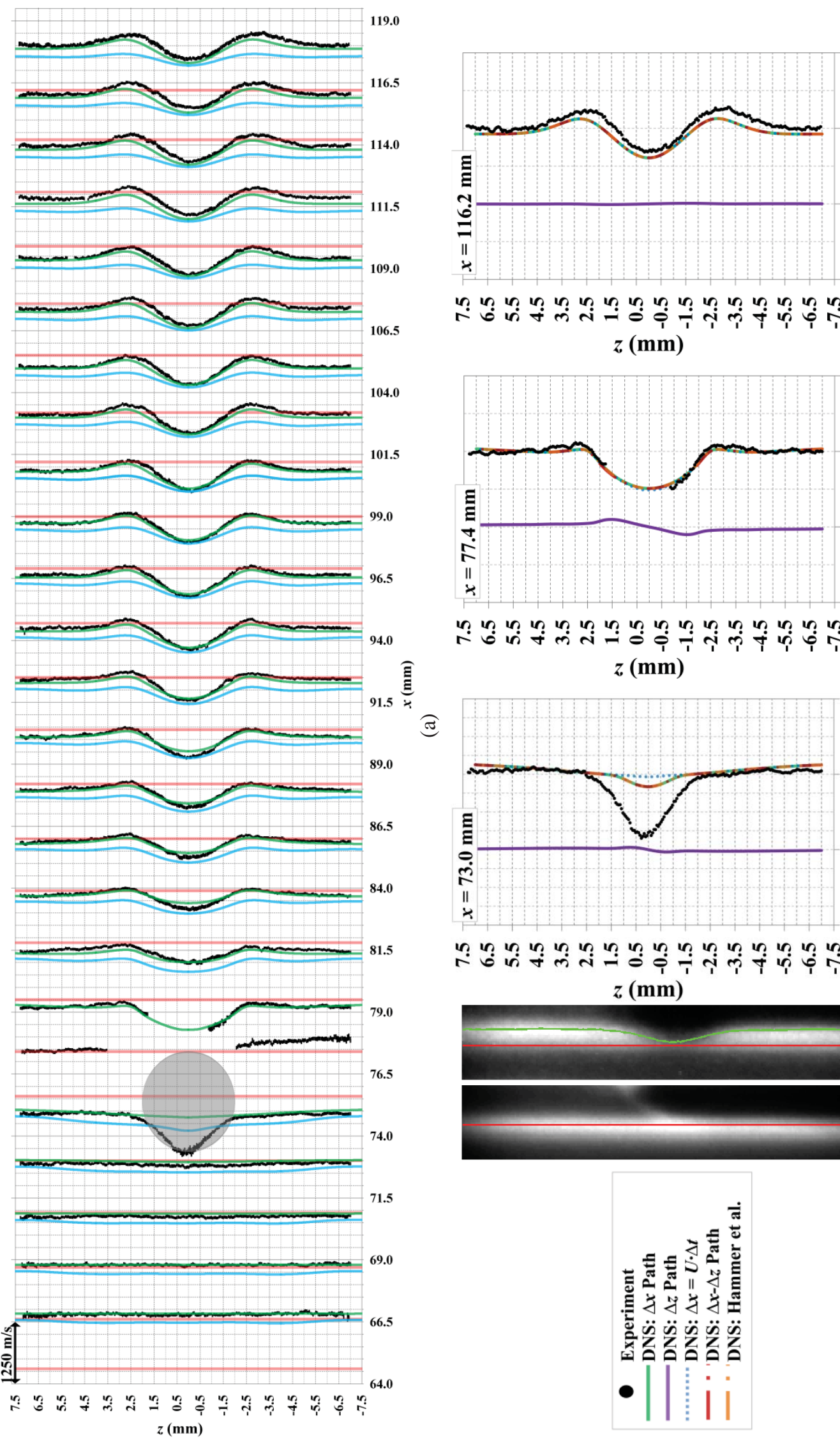

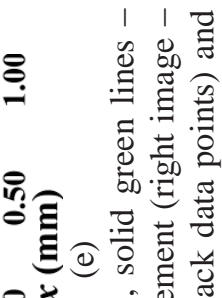

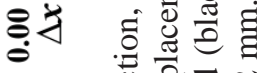

:

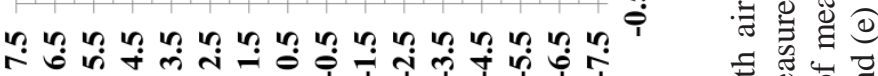

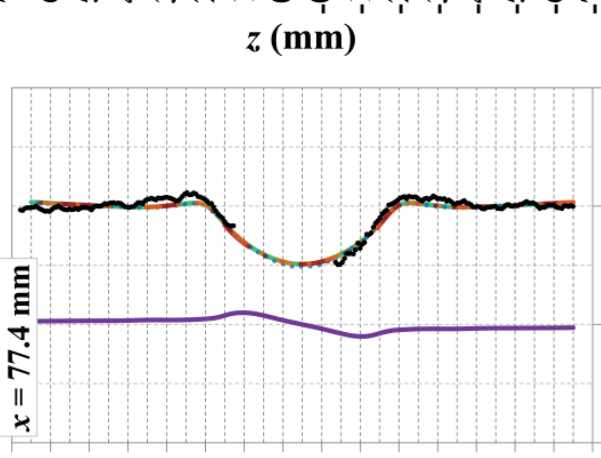

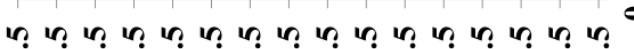

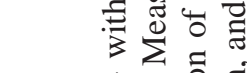

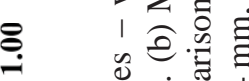

䒠芯实

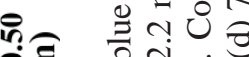

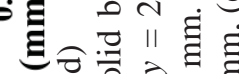

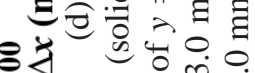

-

픙: :

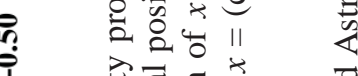

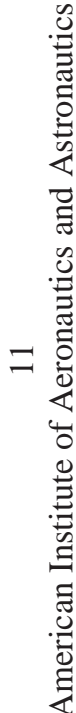

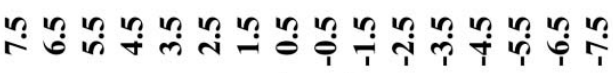
$z(\mathbf{m m})$

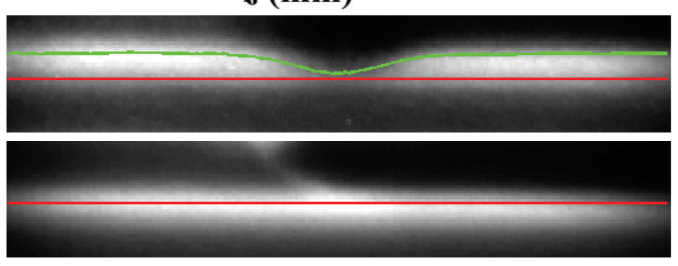

กำ

:ुํํำ

$z(\mathbf{m m})$

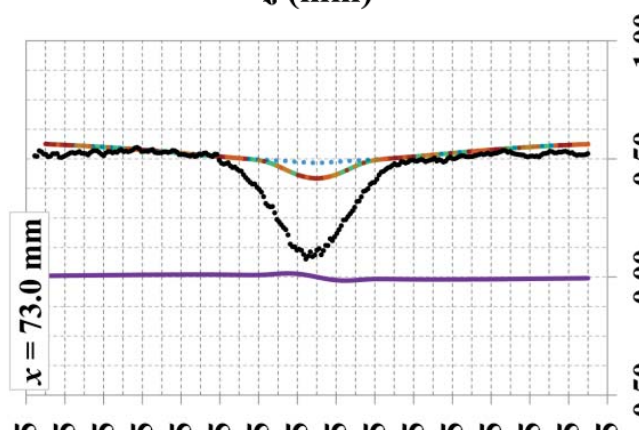

$\Xi$

$>$ 声员.

.

范范.

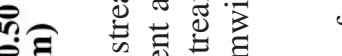

Eิ

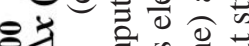

ब

它总壱

ฮี

.

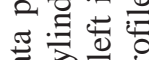

要窎包道

论要泀

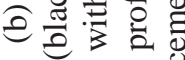

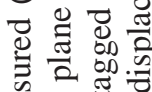

娄

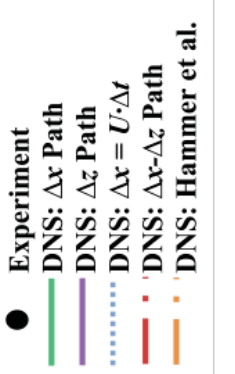

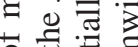

員

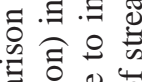

흘. 월

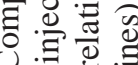

(ี)

$\exists \equiv$

$\ddot{\circ} \bar{z}$

일 


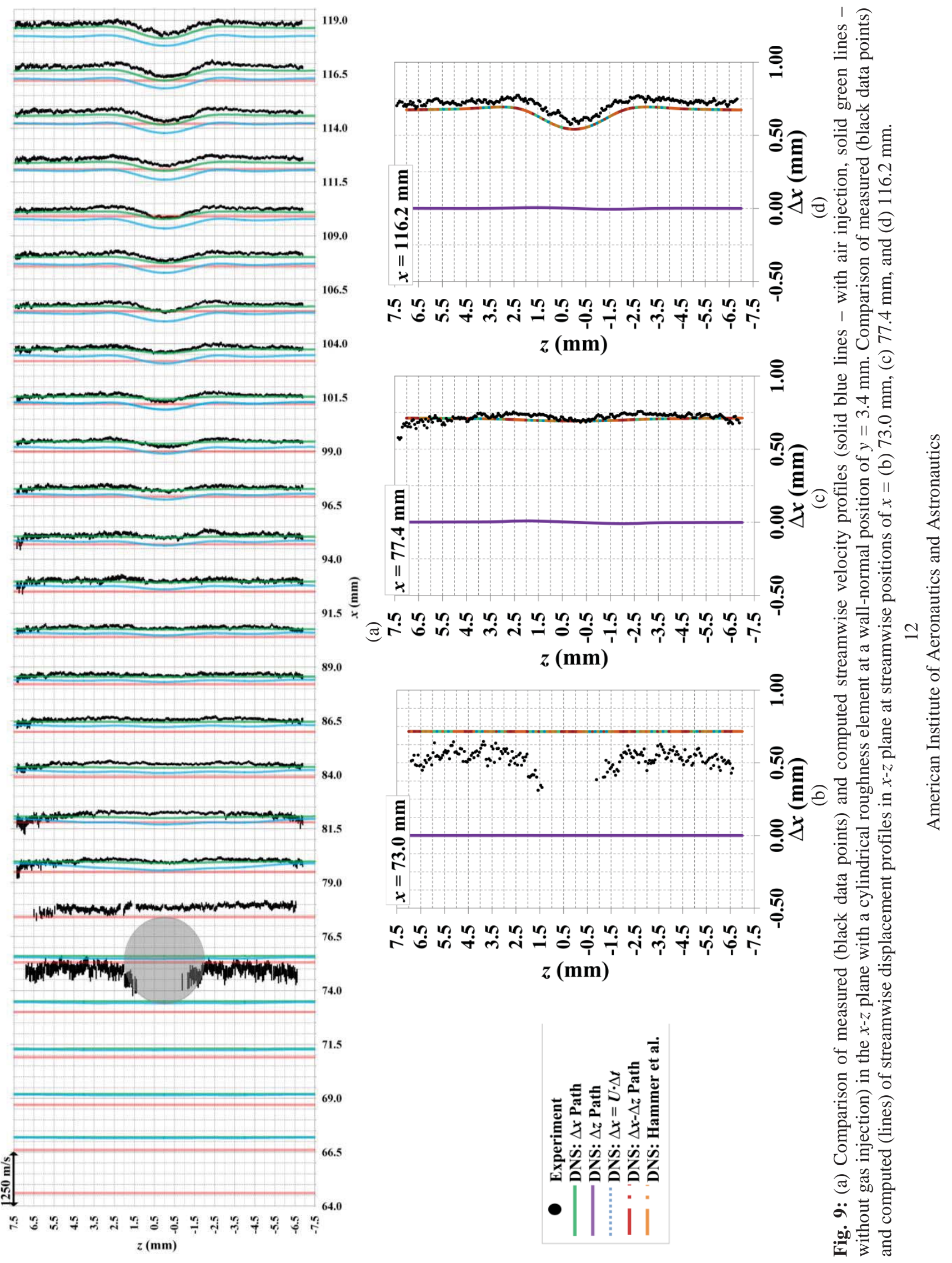


In Fig. 7, the discrepancy between the predicted streamwise velocity profiles and the MTV measurements is greater than at the other wall-normal locations. For the measurements presented in this figure, the error in the profile $x$-locations is estimated to be $\pm 0.31 \mathrm{~mm}$. The light-gray circle corresponds to the wall-normal projection of the isolated cylindrical roughness element. As in Fig. 4a, the mean velocity is indicated by the center of black horizontal data points, with the width corresponding to the uncertainty in the mean. The simulated streamwise velocity profiles shown in this figure were obtained from an $x-z$ plane at a position of $y=0.3 \mathrm{~mm}$. The measurements of streamwise velocity at this wall-normal location are consistently higher than those predicted by the simulation. Prior to processing the image set corresponding to this $y$-location, any images where significant laser scatter from the model surface was observed were discarded from the set, which would otherwise result in measurement errors. Similarly, images in which the laser lines were blocked by the model surface were also discarded. These undesirable occurrences were a consequence of facility vibration causing the wall-normal location of the laser lines to oscillate with respect to the nominal desired position of $y=0.0 \mathrm{~mm}$ (in some cases recessing below the model surface). Due to this vibration and subsequent image rejection process, the remaining images result in streamwise velocity measurements for which the laser lines do not intersect the model surface. Considering that the focused laser lines are approximately $0.7 \mathrm{~mm}$ in diameter, a more appropriate comparison would be for simulated streamwise profiles at $y=0.35 \mathrm{~mm}$.

In the remaining streamwise velocity comparisons between simulation and experiment for the cylindrical roughness element (Figs. 4a, 8a, and 9a), the agreement between the simulation case without air injection and the MTV measurements is generally good away from the roughness element. In Figs. 8a and 9a, the error in the profile $x$-locations is estimated to be $\pm 0.35 \mathrm{~mm}$ and $\pm 0.10 \mathrm{~mm}$, respectively. Near the cylindrical roughness element, however, significant discrepancies between the simulation results and the MTV measurements are observed in the regions immediately adjacent to the roughness element. In the following section, several possible causes for these discrepancies are examined.

\section{B. Analysis of MTV Profile Motion with Cylindrical Roughness Element}

Two key assumptions were made when reporting streamwise velocities obtained from the MTV experiments. The first assumption is that the tagged gas translates in a direction perpendicular to the initially tagged profile. However, if a significant velocity component exists that is parallel to the tagged profile, an error in the reported streamwise velocity component will be incurred. This error is described graphically in Fig. 10a, which is adapted from Fig. 7 in Ref. 37, Fig. 2 in Ref. 38, and Fig. 2 in Ref. 39. In this figure and during the MTV measurement after the first exposure has closed, a point $\left(x_{0}, z_{0}\right)$ along the profile will transit to a new point at $\left(x_{0}+\Delta x, z_{0}+\Delta z\right)$, at which time the second exposure opens. The cross-correlation is then performed between the intensity profile centered at $\left(x_{0}, z_{0}\right)$ in the first exposure and intensity profile centered at $\left(x_{0}+\Delta x_{m}, z_{0}\right)$ in the second exposure, where the subscript $m$ refers to the measured displacement.

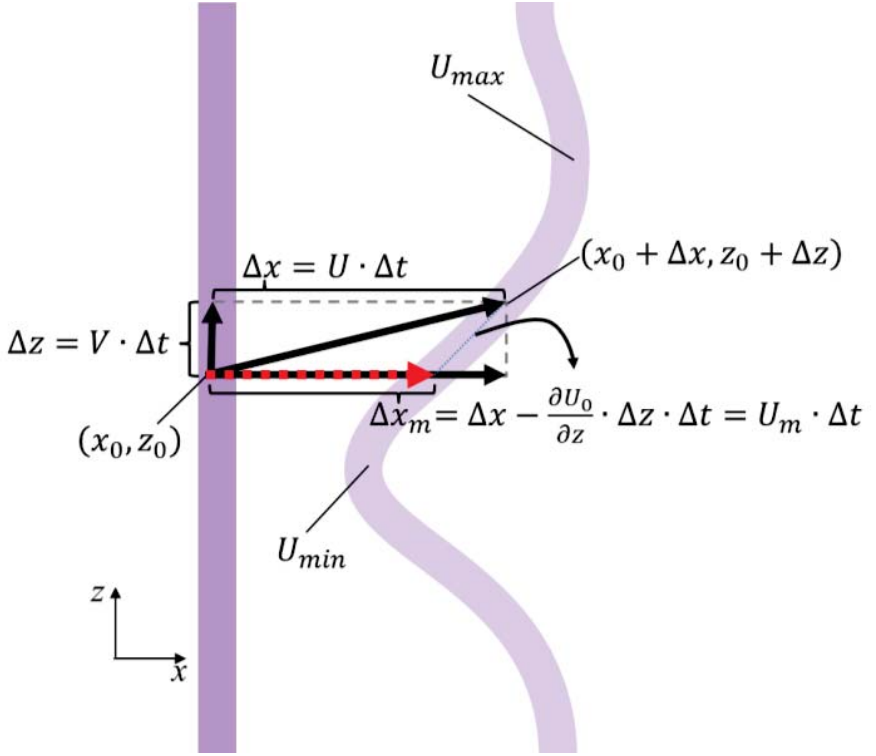

(a)

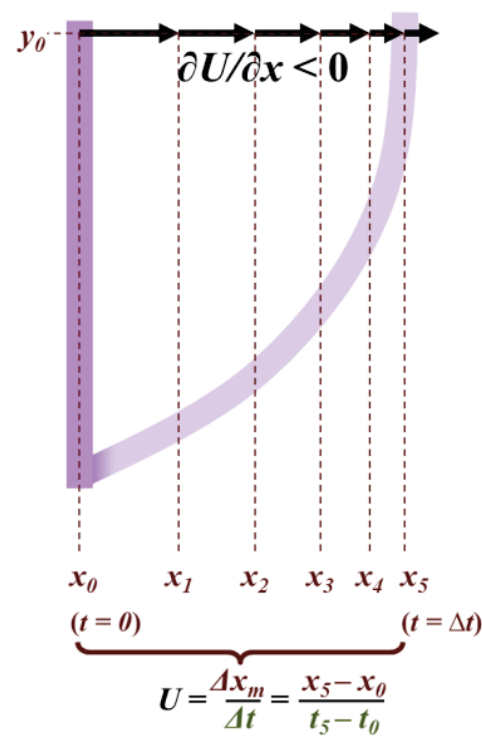

(b)

Fig. 10: (a) Velocity error resulting from velocity component parallel to tagged profile. Modeled after figures taken from Refs. 37, 38, and 39. (b) Influence of velocity gradient on measured streamwise velocity. 
In Fig. 10a, the vertical violet line corresponds to the profile imaged in the first camera exposure and the curved violet profile corresponds to the profile imaged in the second camera exposure. A spanwise velocity component, $V$, results in a measured streamwise velocity of $U_{m}=\Delta x_{m} / \Delta t$ while the true streamwise velocity is $U=\Delta x / \Delta t$.

The error in the streamwise displacement measurement incurred from the presence of the $V$ component of velocity, similar to the derivation in Refs. 37 and 39, is:

$$
\Delta x-\Delta x_{m}=\frac{\partial U_{0}}{\partial z} \cdot V \cdot \Delta t^{2}
$$

Computational results in Fig. 3a show the presence of significant wall-normal velocity components in the immediate vicinity of the cylindrical roughness element.

The second key assumption made when performing the MTV experiments is that the measured streamwise velocity component, $U$, is constant over the duration of the measurement period, $\Delta t$. Put another way, the measured profile displacement relative to the point at which the NO gas is initially tagged, $\left(x_{0}, y_{0}\right)$, is given by the simple relation:

$$
\Delta x_{m, U_{0}=\text { const }}=U_{0} \cdot \Delta t
$$

where $U_{0}$ is the true streamwise velocity magnitude at $\left(x_{0}, y_{0}\right)$. However, if a streamwise velocity gradient exists across the measurement region, an error in the reported streamwise velocity component will be incurred. Such gradients result from the presence of adverse or favorable pressure gradients. This error is described graphically in Fig. 10b. In this figure, the molecules are initially tagged and imaged at a location $\left(x_{0}, y_{0}\right)$ having a local streamwise velocity corresponding to $U_{0}$. During the measurement period $\Delta t$, the tagged molecules proceed downstream in the presence of the negative velocity gradient and experience a deceleration. After $\Delta t$, the tagged molecules, now at a location $\left(x_{5}, y_{5}\right)$, are traveling at the local streamwise velocity $U_{5}<U_{0}$. Since the reported streamwise velocity at $\left(x_{0}, y_{0}\right)$ is inferred from the measured displacement of the tagged molecules, $\Delta x_{m}$, observed over $\Delta t$, the velocity measurement error is approximately $\Delta U=\left|U_{5}-U_{0}\right| / 2$. Computational results in Fig. 3b show the presence of significant streamwise velocity gradients in the immediate vicinity of the cylindrical roughness element.

To determine if the disagreement between the measured streamwise velocity profiles and the simulated streamwise velocity profiles is a consequence of either of the error sources described in Fig. 10, the experimentally measured displacement profiles are compared to several variants of simulated displacement profiles. These comparisons are shown in Figs. 4b - 4e for the side-view orientation and Figs. 8c - 8e and Figs. 9b - 9d for the topview orientation at measurement plane positions of $y=2.2 \mathrm{~mm}$ and $y=3.4 \mathrm{~mm}$, respectively, for the cylindrical roughness experiment.

In these figures, the black data points correspond to experimentally measured displacements, $\Delta x_{m}$. The solid green and solid purple lines in Figs. 4b - 4e correspond to simulated streamwise $(\Delta x)$ and wall-normal $(\Delta y)$ displacements obtained by time-integrating flowfield streamlines. The dotted blue line in Figs. $4 \mathrm{~b}-4 \mathrm{e}$ corresponds to a simulated simple displacement profile obtained by assuming constant streamwise velocity over the measurement period given in Eq. 2. The red dash-dot line in Figs. $4 \mathrm{~b}$ - 4e corresponds to the simulated displacement profile, $\Delta x$, obtained via time-integration of streamlines, but reported at a wall-normal position of $y=y_{0}-\Delta y$. This path-adjusted displacement profile replicates any measurement error associated with a wall-normal velocity component as shown in Fig. 10a. The orange dash-dot line in Figs. 4b - 4e was obtained by using the simulation results and the relation in Eq. 1 (also described by Hammer et al. in Ref. 39) to compute an estimate for the measured displacement profile:

$$
\Delta x_{m, e s t}=\Delta x-\frac{\partial U_{0}}{\partial y} \cdot V \cdot \Delta t^{2}
$$

In Eq. 3, a central difference method was applied to the simulated streamwise velocity profiles to obtain the derivative term, $\partial U_{0} / \partial y$. For the top-view displacement comparisons in Figs. $8 \mathrm{c}-8 \mathrm{e}$ and Figs. 9b - 9d, the

Table 3: Displacement profile integration times.

\begin{tabular}{cc}
\hline \hline Case & Integration Time, $\Delta \boldsymbol{t}$ (ns) \\
\hline Cylindrical roughness, side-view & 652.1 \\
Cylindrical roughness, top-view & 552.1 \\
Hemispherical roughness, side-view & 550.8 \\
\hline \hline
\end{tabular}

14

American Institute of Aeronautics and Astronautics 
displacements and derivatives are all with respect to the spanwise coordinate, $z$, rather than the wall-normal coordinate, $y$, as in Figs. $4 \mathrm{~b}-4 \mathrm{e}$. Table 3 lists the integration times, $\Delta t$, used to compute the simulated displacements.

The simulated displacement profiles farthest from the cylindrical roughness element in the side-view symmetry plane $(z=0.0 \mathrm{~mm})$ shown in Figs. $4 \mathrm{~b}$ and $4 \mathrm{e}$ are nearly indistinguishable from one another. This is expected as the wall-normal velocities and streamwise velocity gradients are negligible at these streamwise locations $(x=52.9 \mathrm{~mm}$ and $x=113.7 \mathrm{~mm}$, respectively). The simulated displacement profiles immediately upstream $(x=72.2 \mathrm{~mm}$, Fig. 4c) and downstream $(x=78.6 \mathrm{~mm}$, Fig. 4d) of the cylindrical roughness element, where the disagreement with the experimental displacement profiles is greatest, are nearly indistinguishable. At these streamwise locations, only the path-adjusted simulated displacement profiles show slightly better agreement with the measurement, but the improvement is still not nearly enough to account for the discrepancy between the measured and simulated profiles.

One concern when analyzing the image data to obtain streamwise velocity and displacement data was that laser scatter from the model surface and the cylindrical roughness element would result in measurement errors. To ensure that such scatter did not contribute to the disagreement between the simulation and experimental results, the displacement profiles were plotted on top of the raw images. These plots are shown below the displacement profile plots in Fig. 4. In these plots, the solid red lines correspond to the location of the initially tagged profile and the solid green lines correspond to the measured displacement relative to the red lines. For each streamwise location shown, the measured displacements show qualitative agreement with the raw image data.

As with the side-view results in Fig. 4, the simulated displacement profiles for the top-view orientations in Figs. 8 and 9 are nearly indistinguishable from one another. The only exception occurs along the profile at $x=73.0 \mathrm{~mm}$ in the $y=2.2 \mathrm{~mm}$ plane in Fig. 8c. In this figure, the simple displacement profile (dotted blue line) computed using Eq. 2 shows noticeable disagreement with the remaining simulated displacement profiles near $z=0.0 \mathrm{~mm}$. This suggests that the velocity gradient immediately upstream of the cylindrical roughness element has an influence on the MTV velocity measurement. However, when comparing the experimental displacement profile with both the path-adjusted profile (red dash-dot) and the profile simulated using Eq. 3 (orange dash-dot), a significant discrepancy is still observed. As in Fig. 4, the measured displacement profile was compared with the raw image data in Fig. 8b to qualitatively determine if laser scatter had an effect on the experimental velocity and displacement measurement. Based on Fig. 8b, it appears that the velocity and displacement measurement agrees with the raw image data. These results suggest a negligible effect of the velocity gradients near the trip as a cause of the discrepancy between experiment and computations.

\section{Comparison of Measured and Simulated Streamwise Velocity Profiles with Hemispherical Roughness}

Figures 11a - 11e show the measured streamwise velocity profiles (black data points) compared with simulated streamwise velocity profiles without air injection (solid green lines) with a side-view orientation at spanwise locations of $z=-1.42 \mathrm{~mm}, z=-0.41 \mathrm{~mm}, z=0.57 \mathrm{~mm}, z=1.58 \mathrm{~mm}$, and $z=2.58 \mathrm{~mm}$, respectively. The error in the profile spanwise $z$-location is estimated to be $\pm 0.4 \mathrm{~mm}$. The light-gray half-circle represents the spanwise projection of the hemispherical roughness element. This projection of the hemisphere appears skewed because the vertical and horizontal axes are not equally spaced. For each of the streamwise velocity comparisons, a significant number of data points near the model surface were removed as a significant level of laser reflection and scatter was observed. For the remaining MTV streamwise velocity measurements, the general agreement with the simulated streamwise velocity profiles without air injection is relatively good. As with the side-view cylindrical roughness case in Fig. 4a, near the axis of symmetry $(z=0.0 \mathrm{~mm})$, a shear layer develops downstream of the hemispherical roughness element at $y=k=2.0 \mathrm{~mm}$. As in Fig. 4a, this shear layer recovers to a Blasius-like shape approximately 10 roughness diameters downstream of the roughness element and is accurately captured by the CFD simulation.

\section{Conclusions}

This paper presented a comparison of measured streamwise velocity profiles in a $M_{e}=8$ hypersonic boundary layer obtained using the nitric-oxide (NO) molecular tagging velocimetry (MTV) technique with DNS simulations. Two flowfield types were considered in this comparison. The first was a flat-plate boundary layer flowfield with a cylindrical roughness element. Simulations of this flowfield were performed both with and without air injection from a rectangular slot upstream of the isolated roughness element. The simulated case with air injection was performed in an effort to model the injection of NO, which was necessary in the experimental MTV measurements. Comparison of the experimental streamwise velocity measurements with the simulation results showed that the simulated case without air injection agreed more closely with the MTV measurements. This result suggests that the NO injection in the MTV experiments has a relatively negligible effect on the hypersonic boundary layer flowfield 
and that the DNS results overestimate the effect of air injection on the flowfield. For velocity profiles away from the cylindrical roughness element, it was determined that the CFD simulation without air injection accurately predicts the streamwise velocity field. For profiles in the immediate vicinity of the cylindrical roughness element, however, significant discrepancies were observed. These discrepancies were initially assumed to be a consequence of streamwise velocity gradients and velocity components parallel to the MTV profiles. A comparison of experimental and CFD simulated streamwise displacement profiles was performed to determine if such flow features did indeed result in the discrepancies observed between the experimental and CFD simulation results. Although streamwise velocity gradients were shown to account for some of the discrepancies-most noticeably in the case of the topview profile located at $x=73.0 \mathrm{~mm}$ and $y=2.2 \mathrm{~mm}$, upstream of the cylindrical roughness element-they generally had little effect on the simulated profiles, thus failing to account for the majority of the observed disagreement with the experimentally measured profiles. The influence of velocity components in the CFD simulation parallel to the MTV profiles on the disagreement between experiment and simulation was negligible.

The second flowfield used for comparison of CFD simulation results with experimental MTV measurements was a flat-plate boundary layer flowfield with a hemispherical roughness element. As with the cylindrical roughness flowfield, the general agreement between the streamwise velocity profile simulation without upstream air injection and the MTV streamwise velocity profiles was relatively good. Unfortunately, laser scatter limited the proximity with which the experimental measurements could be made relative to the model surface.

The reasons for the unexplained discrepancies between computed and measured displacement profiles could be experimental, computational, or both. Experimentally, potential effects of gradients in the local fluorescencequenching environment - which is largely a function of density — should be considered. Computationally, potential ways in which DNS might underestimate the influence of the abrupt perturbations to the flow caused by the tripping elements employed in this study should also be investigated. 


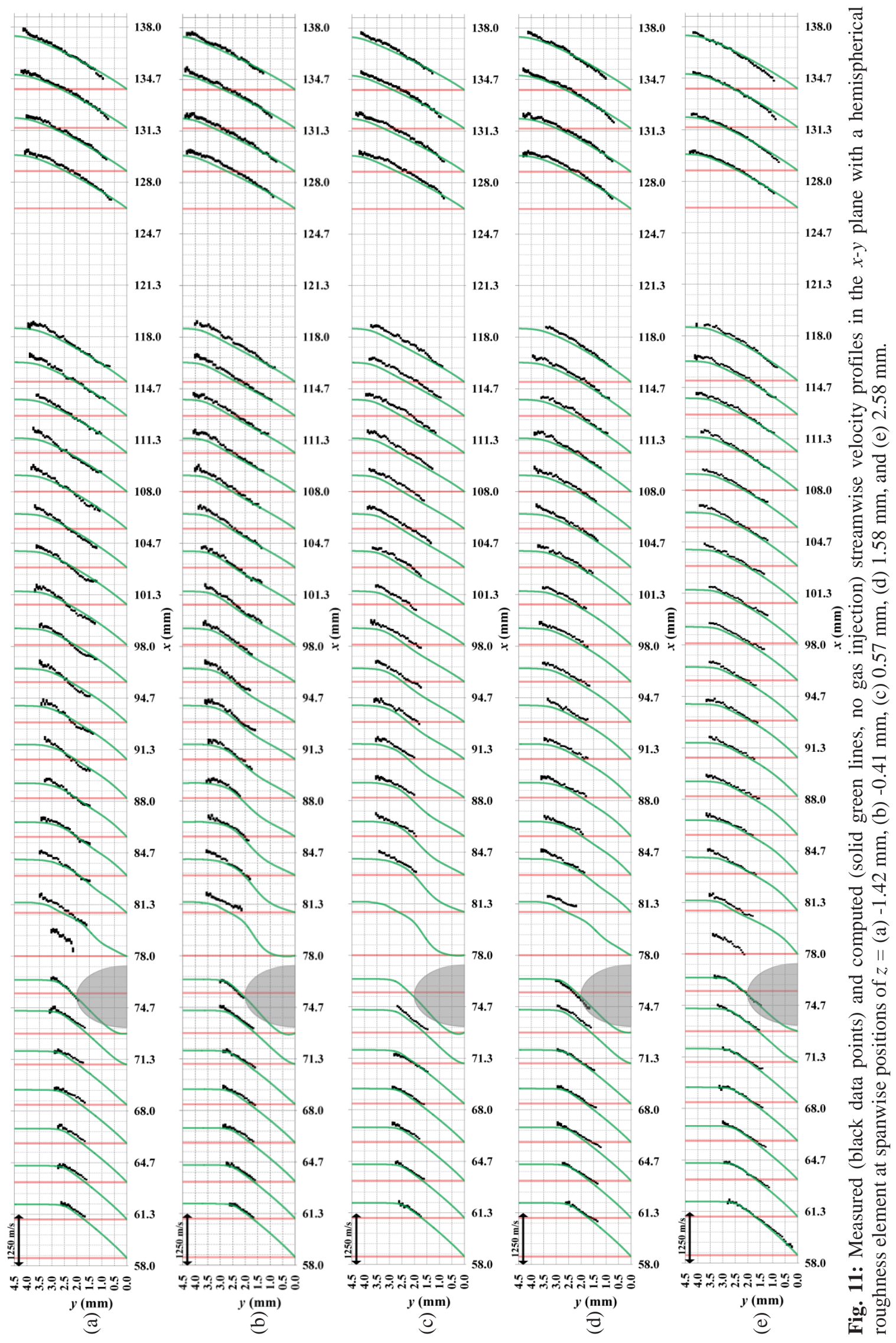




\section{Acknowledgments}

We wish to acknowledge the contribution to this project from the NASA Langley Research Center 31-Inch Mach 10 Air Tunnel technicians and engineers, including Kevin Hollingsworth, Sheila Wright, Tony Robbins, Henry Fitzgerald, Johnny Ellis, Stan Mason, Doug Boggs, and Tim Berry. We also wish to thank Dr. Shann Rufer of the NASA Langley Research Center Aerothermodynamics Branch for helpful discussions on hypersonic transition-toturbulence issues. Dr. Johansen was supported by the Natural Sciences and Engineering Research Council of Canada (NSERC). We also wish to acknowledge the support of the ARMD Fundamental Aeronautics Program's Hypersonics Project and also the new High Speed Project. The UMN research was partially supported by NASA under the Hypersonics NRA program Grant No. NNX08AB33A. Computer time was provided by the Minnesota Supercomputing Institute and the Texas Advanced Computing Center through TeraGrid Allocations.

\section{References}

1 Schneider, S.P., "Effects of Roughness on Hypersonic Boundary-Layer Transition," Journal of Spacecraft and Rockets, 45(2), pp. 193-209, March - April, 2008.

2 Smith, A.M.O., and Clutter, D.W., "The Smallest Height of Roughness Capable of Affecting Boundary-Layer Transition,” Journal of Aerospace Sciences, 26(4), pp. 229-245, April, 1959.

3 Van Driest, E.R., and McCauley, W.D., "The Effect of Controlled Three-Dimensional Roughness on BoundaryLayer Transition at Supersonic Speeds," Journal of Aerospace Sciences, 27(4), pp. 261-271, April, 1960.

4 Reshotko, E., "Roughness-Induced Transition, Experiment and Modeling," $38^{\text {th }}$ AIAA Fluid Dynamics Conference, AIAA 2008-4294, June 23-26, 2008, Seattle, WA.

5 Reda, D.C., "Review and Synthesis of Roughness-Dominated Transition Correlations for Reentry Applications," Journal of Spacecraft and Rockets, 39(2), March-April, 2002, p. 161-167.

6 Reed, H.L, and Saric, W.S., "Linear Stability Theory Applied to Boundary Layers," Annual Review of Fluid Mechanics, 28, pp. 389-428, 1996.

7 Mack, L.M., "Linear Stability Theory and the Problem of Supersonic Boundary-Layer Transition," AIAA Journal, 13(3), pp. 278-289, March, 1975.

8 Malik, M.R., "Prediction and Control of Transition in Supersonic and Hypersonic Boundary Layers," AIAA Journal, 27(11), pp. 1487-1493, November, 1989.

9 Reshotko, E., "Transient Growth: A factor in bypass transition," Physics of Fluids, 13(5), pp. 1067-1075, May, 2001.

10 Federov, A., "Transition and Stability of High-Speed Boundary Layers," Annual Review of Fluid Mechanics, 43, pp. 79-95, 2011.

11 Mack, L.M., "Boundary-Layer Linear Stability Theory,” AGARD Report 709, pp. 3-1 - 3-81, 1984.

12 Reshotko, E., "Transition Issues for Atmospheric Entry," Journal of Spacecraft and Rockets, 45(2), pp. 161-164, March-April, 2008.

13 Reshotko, E., and Tumin, A., "Role of Transient Growth in Roughness-Induced Transition," AIAA Journal, 42(4), pp. 766-770, April, 2004.

14 Wheaton, B.M., Bartkowicz, M.D., Subbareddy, P.K., Schneider, S.P., and Candler, G.V., "Roughness-Induced Instabilities at Mach 6: A Combined Numerical and Experimental Study," $41^{\text {st }}$ AIAA Fluid Dynamics Conference, AIAA 2011-3248, June 27-30, 2011, Honolulu, HI.

15 Iyer, P.S., Muppidi, S., and Mahesh, K., "Roughness-induced transition in high speed flows," $49^{\text {th }}$ AIAA Aerospace Sciences Meeting, AIAA 2011-566, January 4-7, 2011, Orlando, FL.

16 Iyer, P, and Mahesh, K., "High-speed boundary-layer transition induced by a discrete roughness element," Journal of Fluid Mechanics, 729, pp. 524 - 562, August, 2013.

17 Iyer, P.S., Muppidi, S., and Mahesh, K., "Transition of hypersonic flow past flat plate with roughness elements," $40^{\text {th }}$ AIAA Fluid Dynamics Conference, AIAA 2010-5015, June 28 - July 1, 2010, Chicago, IL.

18 Iyer, P.S., Muppidi, S., and Mahesh, K., "Boundary layer transition in high-speed flows due to roughness," $50^{\text {th }}$ AIAA Aerospace Sciences Meeting, AIAA 2012-1106, January 9-12, 2012, Nashville, TN.

19 Tirtey, S.C., Chazot, O., and Walpot, L., "Characterization of hypersonic roughness-induced transition," Experiments in Fluids, 50, pp. 407-418, 2011.

20 Wheaton, B.M., and Schneider, S.P., "Roughness-Induced Instability in a Hypersonic Laminar Boundary Layer," AIAA Journal, 50(6), pp. 1245-1256, June, 2012. 
21 Danehy, P.M., Bathel, B., Ivey, C., Inman, J.A., and Jones, S.B., "NO PLIF study of hypersonic transition over a discrete hemispherical roughness element," $47^{\text {th }}$ AIAA Aerospace Sciences Meeting, AIAA 2009-394, January 5-8, 2009, Orlando, FL.

22 Danehy, P.M., Ivey, C.B., Inman, J.A., Bathel, B.F., Jones, S.B., McCrea, A.C., Jiang, N., Webster, M., Lempert, W., Miller, J., and Meyer, T., "High-Speed PLIF Imaging of Hypersonic Transition over Discrete Cylindrical Roughness," $48^{\text {th }}$ AIAA Aerospace Sciences Meeting, AIAA 2010-703, January 4-7, 2010, Orlando, FL.

23 Jiang, N., Webster, M., Lempert, W.R., Miller, J.D., Meyer, T.R., and Danehy, P.M., "MHz-Rate NO PLIF Imaging in a Mach 10 Hypersonic Wind Tunnel," $48^{\text {th }}$ AIAA Aerospace Sciences Meeting, AIAA 2010-1407, January 4-7, 2010, Orlando, FL.

24 Medford, T.L., Danehy, P.M., Jones, S.B., Bathel, B.F., Inman, J.A., Jiang, N., Webster, M., Lempert, W., Miller, J., and Meyer, T., "Stereoscopic Planar Laser-Induced Fluorescence Imaging at $500 \mathrm{kHz}$," $49^{\text {th }}$ AIAA Aerospace Sciences Meeting, AIAA 2011-985, January 4-7, 2011, Orlando, FL.

25 Chang, C.-L., Choudhari, M.M., and Li, F., "Numerical Computations of Hypersonic Boundary-Layer over Surface Irregularities," $48^{\text {th }}$ AIAA Aerospace Sciences Meeting, AIAA 2010-1572, January 4-7, 2010, Orlando, FL.

26 Bathel, B.F., Danehy, P.M., Inman, J.A., Watkins, A.N., Jones, S.B., Lipford, W.E., Goodman, K.Z., Ivey, C.B., and Goyne, C.P., "Hypersonic Laminar Boundary Layer Velocimetry with Discrete Roughness on a Flat Plate,", $40^{\text {th }}$ Fluid Dynamics Conference and Exhibit, AIAA 2010-4998, June 28 - July 1, 2010, Chicago, IL.

27 Johansen, C.T., Danehy, P.M., "Numerical investigation of PLIF gas seeding for hypersonic boundary layer flows," 50 ${ }^{\text {th }}$ AIAA Aerospace Sciences Meeting, AIAA 2012-1057, January 9-12, 2012, Nashville, TN.

28 Berry, S.A., Nowak, R.J., and Horvath, T.J., "Boundary Layer Control for Hypersonic Airbreathing Vehicles," $34^{\text {th }}$ AIAA Fluid Dynamics Conference, AIAA 2004-2246, June 28 - July 1, 2004, Portland, OR.

29 Micol, J.R., "Langley Aerothermodynamic Facilities Complex: Enhancements and Testing Capabilities," $38^{\text {th }}$ AIAA Aerospace Sciences Meeting, AIAA 1998-147, 1998.

30 Bathel, B.F., Danehy, P.M., Inman, J.A., Jones, S.B., Ivey, C.B., and Goyne, C.P., "Velocity Profile Measurements in Hypersonic Flows Using Sequentially-Imaged Fluorescence-Based Molecular Tagging Velocimetry," AIAA Journal, Vol. 49, No. 9, September 2011.

31 Park, N., and Mahesh, K., "Numerical and modeling issues in LES of compressible turbulence on unstructured grids," 45th AIAA Aerospace Sciences Meeting and Exhibit, AIAA 2007-722, January 8-11, 2007, Reno, NV.

32 Muppidi, S., and Mahesh, K., "Direct numerical simulations of roughness-induced transition in supersonic boundary layers," Journal of Fluid Mechanics, 693, pp. 28 - 56, February, 2012.

33 Muppidi, S., and Mahesh, K., "DNS of transition in supersonic boundary layers," $40^{\text {th }}$ AIAA Fluid Dynamics Conference, AIAA 2010-4440, June 28 - July 1, 2010, Chicago, IL.

34 Chai, X., and Mahesh, K., "Simulations of high speed turbulent jets in crossflows," 49th AIAA Aerospace Sciences Meeting and Exhibit, AIAA 2011-650, January 4-7, 2011, Orlando, FL.

35 Muppidi, S., and Mahesh, K., "DNS of unsteady shock boundary layer interaction," $49^{\text {th }}$ AIAA Aerospace Sciences Meeting and Exhibit, AIAA 2011-724, January 4-7, 2011, Orlando, FL.

36 Arisman, C.J., Johansen, C.T., Galuppo, W.C., and McPhail, A., "Nitric Oxide Chemistry Effects in Hypersonic Boundary Layers," 43 ${ }^{\text {rd }}$ AIAA Fluid Dynamics Conference, AIAA 2013-3104, June 24-27, 2013, San Diego, CA.

37 Hill, R.B., and Klewicki, J.C., "Data reduction methods for flow tagging velocity measurements," Experiments in Fluids, 20(3), pp. 142 - 152, January, 1996.

38 Koochesfahani, M.M., Cohn, R.K., Gendrich, C.P., and Nocera, D.G., "Molecular Tagging Diagnostics for the Study of Kinematics and Mixing in Liquid-Phase Flows," 8th International Symposium on Applications of Laser Techniques to Fluid Mechanics, pp. 1.2.1 - 1.2.12, Lisbon, Portugal, July 8-11, 1996.

39 Hammer, P., Pouya, S., Naguib, A., and Koochesfahani, M., "A multi-time-delay approach for correction of the inherent error in single-component molecular tagging velocimetry," Measurement Science and Technology, 24, 2013. 